\title{
Consumo de alcohol, dependencia alcohólica, trastornos relacionados con el alcohol en España. Impacto de los tratamientos de la dependencia alcohólica
}

\section{Alcohol consumption, alcohol dependence and related harms in Spain, and the effect of treatment-based interventions on alcohol dependence}

\author{
JÜRGEN REHM ${ }^{\star * \star \star \star * ; ~ M A X I M I L I E N ~ X . ~ R E H M ~}{ }^{\star \star \star \star \star * ; ~}$ \\ KeVIN D. ShIELD****; GeRRIT GMeL ${ }^{\star *}$; \\ ANTONI GUAL ${ }^{\star \star \star \star * \star *}$
}

* Institute for Clinical Psychology and Psychotherapy, TU Dresden, Germany.

** Centre for Addiction and Mental Health (CAMH), Toronto, Canada.

*** Institute of Medical Science, University of Toronto, Canada.

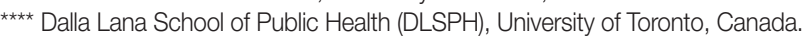

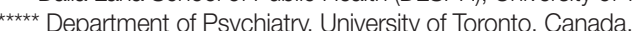

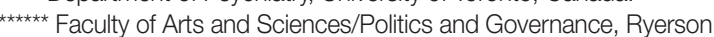

University, Toronto, Canada.

Alcohol Unit, Psychiatry Dept., Neurosciences Institute, Hospital Clinic,

IDIBAPS, Barcelona, Spain.

Enviar correspondencia a:

Kevin D. Shield

CAMH 33 Russell Street

Toronto, Ontario, Canada, M5S 2S1

E-mail: Kevin.shield@mail.utoronto.ca

Phone: +16479716175

Fax: +1416 2604146

recibido: Mavo 2012 aceptado: Agosto 2012

\section{Resumen}

El consumo de alcohol en España ha seguido tradicionalmente los patrones mediterráneos: consumo diario en las comidas, preferentemente cerveza y comparativamente poco consumo dirigido a la intoxicación. La dependencia alcohólica (AD), una de las enfermedades más deteriorantes provocadas por el alcohol, tiene una prevalencia del $0.2 \%$ en mujeres y del 1.2\% en hombres, lo que significa que unas 31,200 mujeres y 186,000 hombres en España padecian AD en 2005 en el grupo etario comprendido entre 15 y 64 años. Estas prevalencias son probablemente estimaciones a la baja, debidas básicamente a limitaciones en el World Mental Health Survey que no son susceptibles de ser corregidas. Sin embargo, dichas estimaciones son las mas actualizadas y fiables en la actualidad. El alcohol genera importantes costes para la salud en España: 11.3 muertes prematuras por 100.000 en mujeres entre 15 y 64 años, y 40.9 muertes prematuras por 100.000 hombres en el mismo grupo etario fueron debidas al consumo de alcohol (datos del 2004). Ello significa que el 8.4\% de todas las muertes en mujeres y el $12.3 \%$ en varones de este grupo etario son atribuibles al alcohol. Un elevado porcentaje de estas muertes fueron debidas al consumo muy elevado de alcohol y a la AD. La AD está infratratada en España. Menos del 10\% de los afectados por AD reciben tratamiento. Entre los que reciben tratamiento, la psicoterapia es el método mas utilizado para prevenir recaídas. Si el $40 \%$ de pacientes $A D$ en España siguieran tratamiento farmacológico (el tratamiento mas efectivo), $2.2 \%$ de las muertes provocadas por $A D$ en mujeres $y$ $6.2 \%$ en hombres, se podrian prevenir en un año. Así pues, incrementar las tasas de tratamiento puede ser un instrumento eficaz para reducir los costes para la salud y la mortalidad atribuibles al alcohol en España.

Palabras clave: Alcohol, dependencia, mortalidad, tratamiento, España.

\section{Abstract}

Alcohol consumption in Spain has traditionally followed the Mediterranean drinking pattern, featuring daily drinking with meals, beer as the preferred beverage, and comparatively little drinking to intoxication. Alcohol dependence (AD), one of the most detrimental disorders caused by alcohol, was prevalent in $0.2 \%$ of women and $1.2 \%$ of men, corresponding to 31,200 women and 186,000 men in Spain with $A D$ in 2005 in the age group of 15 to 64 year. These prevalence estimates of alcohol dependence are likely underestimated due to limitations in the World Mental Health Survey which cannot be fully corrected for; however, the estimates of $A D$ for Spain represent the most accurate and up to date estimates available. Alcohol creates a significant health burden in Spain with 11.3 premature deaths in women per 100,000 aged 15 to 64 years, and 40.9 premature deaths in men per 100,000 in the same age group were due to alcohol consumption (data for 2004). This amounts to $8.4 \%$ of all female deaths and $12.3 \%$ of all the male deaths in this age group being attributable to alcohol consumption. A large percentage of these harms were due to heavy alcohol consumption and AD.

$A D$ is undertreated in Spain, with less than $10 \%$ of all people with $A D$ treated. For those who are treated, psychotherapy is the most utilized form of treatment to avoid relapse. If $40 \%$ of $A D$ patients in Spain were treated with pharmacological treatment (the most effective treatment method), $2.2 \%$ of female and $6.2 \%$ of male deaths due to $A D$ would be prevented within one year. Thus by increasing treatment rates is an important means of reducing the alcohol-attributable mortality and health burden in Spain. 
A Icohol consumption is deeply ingrained in the European culture and mindset, unlike anywhere else in the world. Traditionally, the Spanish drinking culture seems to follow the Mediterranean pattern of drinking, with a strong emphasis on regular consumption of alcohol with a relatively high proportion of daily drinkers, often drinking with meals; wine as the traditional beverage of choice; avoidance of irregular heavy drinking; and a high tolerance of the social outcomes of drinking, but no acceptance of public drunkenness (Gual, 2006; Anderson y Baumberg, 2006; Rehm, Shield, Rehm, Gmel, \& Frick, 2012). However, this pattern has been changing, with an increase in recent years of more irregular heavy drinking occasions and phenomena such as public drinking on festive occasions by youth and young adults (botellón) ((Valencia-Martin, Galán, y Rodriguez-Artalejo, 2007), but see the relative stability up to 2001 (Gual, 2006)).

For 2009, the last year for which data are available, adult per capita consumption ${ }^{1}$ in Spain was around the European Union (EU) average, with 13.1 litres (I) of pure alcohol consumed (the EU average is $12.5 \mathrm{I}$ ). Beer is currently the most consumed beverage (4.8 I of pure alcohol adult per capita), followed by wine (3.9 I) and spirits (2.3 I). Other beverages do not play a large role (data from the last survey of the World Health Organization (WHO)/Europe and the Global Information System on Alcohol and Health (GISAH); http://apps.who.int/ ghodata/?theme $=$ GISAH). This is in contrast to the situation in Spain in the mid-1970s, where overall consumption levels were close to 20 I of pure alcohol adult per capita (1975: 19.5 I), with wine accounting for almost $60 \%$ of all alcohol consumed (11.6 I) (all data from GISAH; see also (World Health Organization 2004; World Health Organization 2011)). See Figure 1 for the trends in recorded alcohol consumption by beverage type from 2000 to 2009.

Trends in alcohol consumption over the years $2000-2009$ show a continuation of the decrease in total consumption which began in the mid-1970s, driven by a decrease in the consumption of wine and spirits, coupled with a small increase in the consumption of beer. The main reductions in overall consumption were driven by a decline in wine consumption pre-2000, not only in Spain, but also in all European wine drinking countries (for reasons see (Gual \& Colom, 1997).

We have combined adult per capita consumption data with survey information to derive indicators for calculating alcohol-attributable harms (Rehm et al., 2010b). For survey information, we used the GENACIS survey (for a short characterization see (Plant et al., 2010)), which had similar abstention and drinking rates to those obtained from the Household Surveys on Drugs as part of the National Plan on Drugs (Gual, 2006). Spain is characterized by a high level of lifetime drinking (M: 90.5\%; W: 75.3\%), but many people quit drinking in older age, in some cases for health reasons.

To gain perspective on how alcohol is consumed in Spain, one can look at a sample of statistics: first, Spain's pattern

1 Consistent with WHO definitions, adult per capita consumption is defined as litres of pure alcohol consumed in a given year, divided by the population aged 15 years and older.

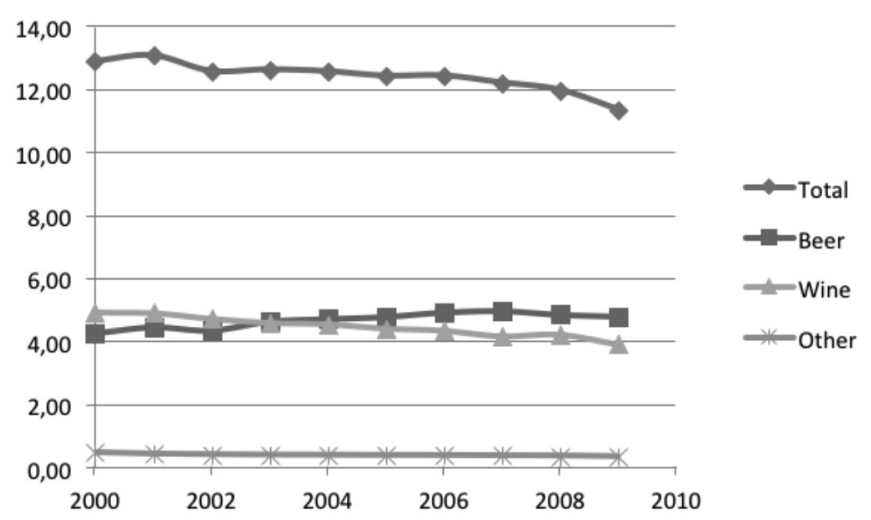

Figure 1: Trends in recorded alcohol consumption in Spain since 2000

of drinking score in 2005 was the least detrimental at 1 (on a scale from 1 to 5 ). This scale, developed as part of the Comparative Risk Assessment study within the Global Burden of Disease study (Rehm et al., 2003; Rehm et al., 2004) is a composite measure assessing at the population level the manner in which individuals consume alcohol. In Spain's case, the pattern of drinking score suggests relatively few binge drinking occasions (risky single occasion drinking, which is potentially far more detrimental than drinking the same amount over the course of a week), relatively little drinking to intoxication, and frequent drinking with meals. However, as indicated above, the pattern of drinking in Spain has been changing in recent years, and irregular heavy drinking occasions have increased. In 2009, among drinkers, 19\% in Spain binged (more than 5 drinks on one occasion) at least once a week, and $13 \%$ binged at least once a month but less than at least once a week (European Commission 2010). These are fairly average numbers for Europe, which generally has the best pattern of drinking scores in a global comparison (aside from some countries in Northern and Central-Eastern Europe). Mainly due to the increase in bingeing outlined above, Spain's pattern of drinking score may increase if current trends continue.

Both average volume of alcohol consumption and patterns of drinking were combined to calculate alcohol-related health harms (for general discussion (Rehm et al., 2004; Rehm et al., 2010a)), the methods used to calculate the number of alcohol attributable deaths are outlined in web appendix 2 and the sources for Relative Risks are outlined in web appendix 3.

\section{Alcohol-attributable harms}

Even though alcohol is generally being consumed in a less detrimental way in Spain compared to other countries (World Health Organization, 2011), alcohol consumption still creates a significant health burden. All of the following statistics are for adults aged 15 to 64 years. i.e., we are mainly concerned with premature deaths and disability.

In Spain, 5,974 male deaths and 1,611 female deaths (total deaths: 7,585) were estimated to be attributable to alcohol consumption in the year 2004. This represented 11.3 deaths in women per 100,000 and 40.9 deaths in men per 100,000 
due to alcohol consumption in this age group (15-64 years). These data placed alcohol-related deaths in Spain in 2004 in the bottom half of European countries. The percentage of all deaths attributable to alcohol in 2004 was $8.4 \%$ for women and $12.3 \%$ for men. Thus, approximately 1 in every 12 women and 1 in every 8 men were estimated to have died prematurely before age 65 due to alcohol-attributable causes in 2004.

A local study seemed to have found considerably lower rates for the same year (Fierro, Ochoa, Yáñez, Valderrama, y Álvarez 2008). However, the estimates of the local study are not comparable with the results we have outlined above for the following reasons: first, and most importantly, Fierro and colleagues (Fierro, Ochoa, Yáñez, Valderrama, \& Álvarez, 2008) dealt with all deaths and not only premature deaths. Since the average age for alcohol-attributable deaths is relatively low (Rehm, Taylor, \& Room, 2006), the proportion of alcohol-attributable deaths always is higher in premature deaths compared to all deaths. Second, the Spanish study used an earlier version of a US standard software to determine attributable fractions, which does not include the latest knowledge with respect to alcohol-attributable mortality (Rehm et al., 2010a).

With respect to Potential Years of Life Lost (PYLL) in 2004, 26,502 and 110,562 PYLL were estimated to be due to the detrimental health effects of alcohol for women and men respectively aged 15 to 64 years. PYLL are a statistic, where not only the number of deaths is relevant but also when in the life course the death occurred. PYLL then are calculated by subtracting the age at time of death from the conditional life expectancy.
The alcohol-attributable Years Lived with Disability (YLD) were 9,384 for women and 52,208 for men, which, in relation to the population size, were among the lowest YLD rates in Europe. Combining these two statistics provides the Disability-Adjusted Life Years (DALYs), which is the sum of years of potential life lost due to premature mortality and the years of productive life lost due to disability. One DALY thus is either one year of life lost due to premature mortality or one year of life lost with disability. A year of life lost with disability takes into account the level of disability and the length of time a person will be disabled.

Alcohol-attributable DALYs (per 100,000) were 247.02 for women and 1,082.92 for men, placing Spain in a relatively favorable 24th/25th place in Europe for women and men, respectively. However, Europe globally is the region with the largest alcohol-attributable harm. The percentage of overall health burden that alcohol consumption imposed on society was $2.9 \%$ for women and $9.4 \%$ for men as measured in DALYs. Consistent with the above-noted mortality burden, these are among the lowest numbers in Europe; for comparison, neighbouring Portugal's statistics for the percentage of alcohol-attributable health burden were markedly higher at $5.3 \%$ for women and $15.0 \%$ for men.

In Spain, 5,476 deaths (928 for women and 4,548 for men) were estimated to be attributable to heavy alcohol consumption (defined as men consuming on average over 60 grams of pure alcohol per day, or 6 standard drinks; and women consuming on average over 40 grams of pure alcohol per day, or 4 standard drinks). When compared to the overall number of alcohol-attributable deaths. the number of deaths
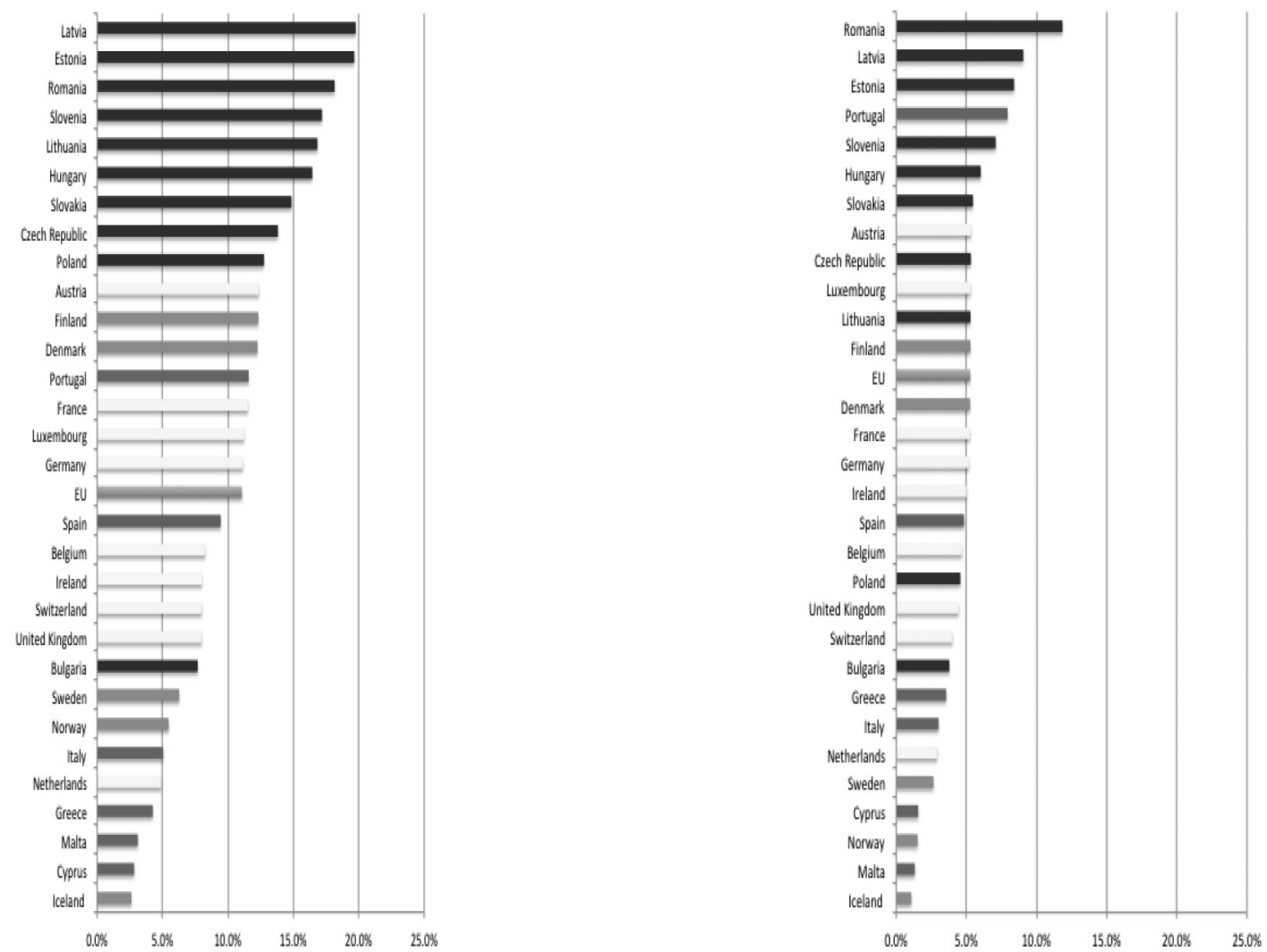

Figure 2: The percentage of deaths attributable to heavy consumption of alcohol by country and sex (men left and women right side) 
attributable to heavy consumption accounted for $72.2 \%$ of all alcohol-attributable deaths in Spain (57.6\% for women and $76.1 \%$ for men). Figure 2 shows the percentage of all deaths attributable to heavy consumption of alcohol by country and by sex.

158,316 (28,484 for women and 130,832 for men) DALYs were attributable to heavy alcohol consumption, constituting $80.2 \%$ (79.4\% for women and $80.4 \%$ for men) of the total alcohol-attributable DALYs in Spain for 2004. In contrast to Spain, in Portugal 87.6\% (93.9\% for women and 85.9\% for men) of the total alcohol-attributable DALYs were attributable to heavy alcohol consumption.

The social costs of alcohol misuse are high: it has been estimated that the direct and indirect costs of alcohol in Spain amounted to 2.7 billion Euros in 2007, accounting for $0.2 \%$ of Spain's GDP in that year (Ivano, Garcia-Altes, \& Nebot, 2011). However, the authors indicate the limitations of their study, as major cost factors were not included. In fact other studies on social costs of alcohol misuse for European countries find usually more than 1\% of GDP ((Rehm et al., 2009) report on 1.4\% of GDP for France and 1.4\% for Scotland; for European estimates of 1.3\% of GDP see (Anderson y Baumberg, 2006; Rehm, Shield, Rehm, Gmel, \& Frick, 2012)). Thus, we would conservatively estimate the real costs of alcohol misuse in Spain to be around 1\% GDP as well, if all the cost factors are included.

\section{Alcohol Dependence and Treatment System}

One of the most severe health consequences of alcohol consumption is alcohol dependence (AD), resulting in a higher chance of alcohol-attributable diseases (such as liver cirrhosis) and potentially leading to severe social problems (e.g. loss of productivity, divorce), as well as creating large potential social costs, for example for treatment.

The prevalence of $A D$ in Spain, based on a survey conducted between 2001 to 2003 (adjusted for underestimation using data from the German Mental Health Survey), was estimated to be $0.2 \%$ for women and $1.2 \%$ for men (based on the World Mental Health Survey. Kessler y Üstün, 2008; ESEMeD/ MHEDEA 2000 Investigators 2004). This corresponds to 31,200 women and 186,000 men in Spain with AD in 2005. The World Mental Health Survey questions about AD were only asked of respondents who had already scored positively on questions regarding alcohol abuse, leading to an underestimation of $A D$ (Grant et al., 2007). Accordingly, these data were combined with data from the German Mental Health Survey, where both dependence and abuse were assessed independently (Jacobi et al., 2004; Jacobi, Wittchen, Holting, Sommer, \& Lieb, 2002). However, this combination of data can only correct for some of the underestimation, as in countries with the Mediterranean style of drinking the proportion of $A D$ to alcohol abuse is usually larger than is observed in countries with higher rates of drinking outside of meals and more irregular binge drinking.

For the sake of comparison, Portugal had a prevalence of $A D$ of $1.7 \%$ for women and $5.6 \%$ for men, and the prevalence of $A D$ in Italy is estimated to amount to $2 \%$ for both sexes. A recent, general, large population survey in Spain used a standardized instrument, the Alcohol Use Disorders Identification Test (AUDIT) from the WHO, and found that $1.4 \%$ of men and $0.3 \%$ of women were above a score of 15 , which indicates a potential alcohol use disorder(Encuesta Domiciliaria sobre Alcohol y Drogas en ESpaña (EDADES) 2009). These prevalence estimates are slightly higher than the AD prevalence estimates outlined above. Overall, since loss of control and other symptoms of $A D$ are tabooed in Spain and Italy (Room y Mäkelä 2000), these numbers can be considered underestimates.

It is also important to understand the treatments available to those who are afflicted by AD. Spain has a professional guideline outlining how $A D$ treatment is to be administered (Guardia Serecigni, Arriero, Pastor, Menéndez, \& Guillamón, 2008), as well as a separate guideline that is used by general practitioners (Ministerio de Sanidad y Consumo, 2008). Generally, treatment is abstinence-based, meaning that most treatment plans have the goal of accomplishing permanent abstinence from alcohol consumption. However, reduced drinking is generally deemed an acceptable treatment outcome for less severe dependence, as an alternative when abstinence fails, as an intermediate goal to achieving abstinence, or as an option potentially requested by the patient.

The psychotherapy administered to $A D$ patients is mainly Cognitive Behavioral Therapy (CBT) and Motivational Interviewing (MI) as well as Group Therapy. These treatment options are among the most frequently used in Europe. Pharmacotherapy is also used in the form of acamprosate, disulfiram, naltrexone and topiramate to aid in treatment to prevent relapse.

\section{Effects of potential treatment interventions}

Overall, even though the amount of alcohol consumed in Spain in high (slightly above the European average and Europe is the region with the highest consumption in the world), because of the manner in which it is consumed, we expect relatively less harm attributable to alcohol consumption compared to other European countries. However, the situation can still be improved by implementing potential treatment interventions and, more importantly, by increasing the proportion of people with $A D$ who are being treated (as indicated above, AD is markedly undertreated in Europe).

We have simulated the potential effects of five different interventions: pharmacological treatment (based on the Cochrane reviews: (Rösner et al., 2010b; Rösner et al., 2010a), MI/CBT (Motivational Interviewing/Cognitive Behavioral Therapy) (Smedslund et al., 2011; Magill y Ray 2009); MI/ CBT assuming the upper level of effectiveness, BI (Brief Intervention) in a hospital setting 1 (McQueen, Howe, Allan, Mains, y Hardy 2011) and BI hospital 2. (See web appendix 4 for the assumptions used for these interventions and web appendix 5 for the methodology used to model the interventions.)

As is the case in almost all other countries in Europe, we estimated that the most effective intervention overall would 
be an increase in pharmacological treatment, with brief interventions in hospitals being almost at the same level. If $20 \%$ of people with AD were treated, we estimated that $1.1 \%$ of all female alcohol-attributable deaths and $3.2 \%$ of all male alcohol-attributable deaths could be prevented within one year ${ }^{2}$. Increasing availability of treatment to $40 \%$ of people with $A D$ would result in the prevention of $2.2 \%$ of all female alcohol-attributable deaths and $6.2 \%$ of all male alcoholattributable deaths within one year (please see detailed results in the country profile below). Of course, there would be additional effects on the long term since some diseases have a longer latency period.

The effects of the interventions in Spain are smaller compared to other countries in Europe. In fact, potential interventions for women are the least effective among all the compared countries (for men, Spain ranks 27 out of 30 countries). The main reason for these results is the assumed low prevalence of AD which, as discussed above, is likely to be an underestimate. We have, therefore, conducted three sensitivity analyses; the results for the treatment of $40 \%$ of people with $A D$ are shown below. These sensitivity analyses use the prevalence numbers based on the EDADES survey (see above), the average prevalence from all countries in the Southern European region, which may be the most realistic estimate, and the EU average as alternative input.

In general, the estimated number of lives saved (or deaths avoided, to be technically more correct) is proportional to the prevalence of $A D$ in the population, and thus all sensitivity analyses show higher impact than the main analyses. The approximately linear relationship between prevalence of $A D$ in the general population and potential gains from treatment is especially true for relatively small ratios between the original prevalence and assumptions in the sensitivity analyses. The prevalence of women scoring 15 or above in the AUDIT is $50 \%$ higher than the prevalence of AD. The prevalence of men with an AUDIT score of 15 or above is around 17\% higher than the prevalence of $A D$. The estimated number of lives saved in men when applying the prevalence of AUDIT $15+$ to people with AD is between $10 \%$ and $17 \%$ higher than the estimates obtained in the main analyses, and the estimated number of lives saved for women under the same circumstances is between $45 \%$ and $55 \%$ higher.

$A D$ is 4.5 times more prevalent in the EU than in Spain for men and 7.5 times more prevalent in the EU than in Spain for women. The sensitivity analyses show a fourfold increase in lives saved for men (from 187 to 763 lives for the intervention with the greatest effect) and a sixfold increase in lives saved for women (from 15 to 95 lives for the intervention with the greatest effect) when using AD values of the EU with the Spanish drinking population. Similarly, compared to Spain, AD in the Southern European Region is 1.4 times more prevalent for men and 3 times more prevalent for women. The magnitude of these ratios is reflected in the increase of lives saved when using the AD values of Southern Europe with the Spanish drinking population. The relative change in lives saved is preserved across all five interventions.

\section{Conclusions}

A marked proportion of alcohol-attributable deaths can be prevented by improving the coverage of treatment for AD. This

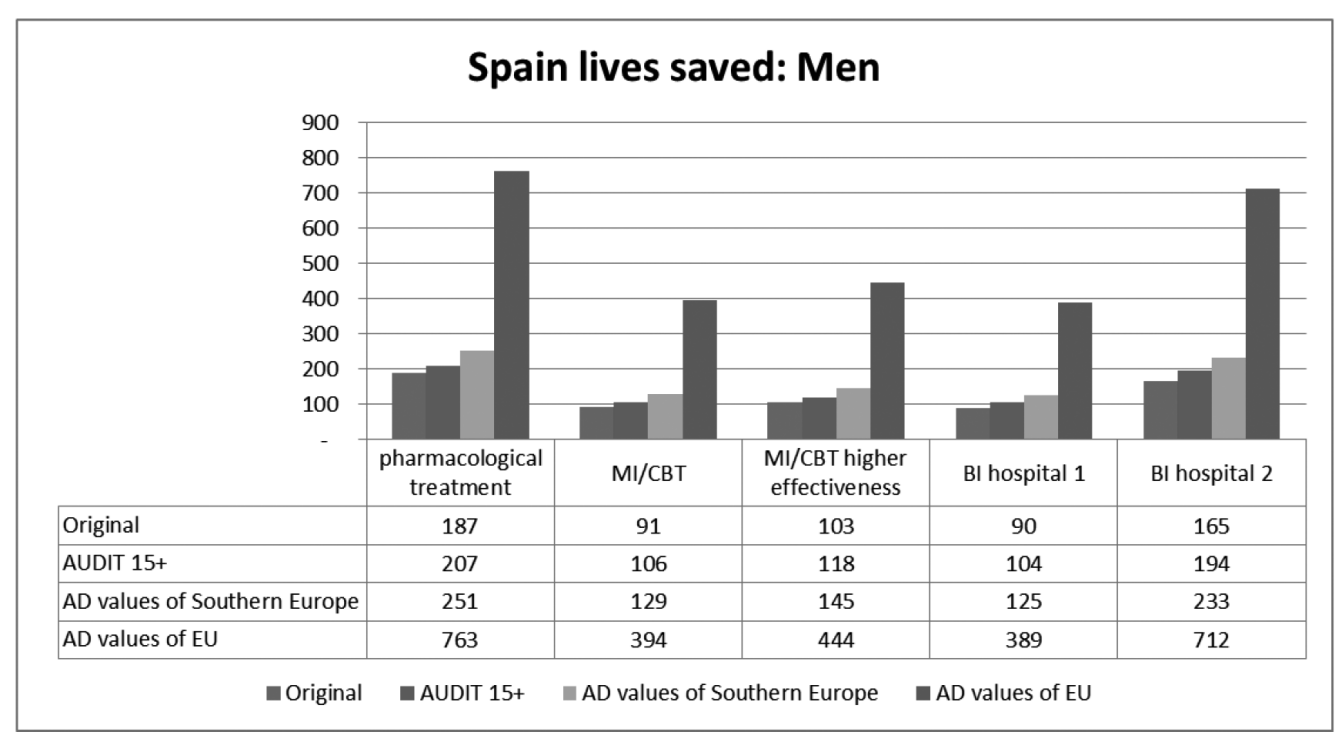

Figure 3: Results for pharmacological interventions in Spain assuming 40\% coverage (i.e. $40 \%$ of all people with $A D$ are treated): main analysis and sensitivity analyses assuming prevalence of $A D$ in Southern European region and prevalence of $A D$ in $E U-$ for men

2 Please note that these numbers are for one year and do not include alcohol-attributable cancers, and thus the absolute numbers slightly differ from all alcohol-attributable deaths above. 


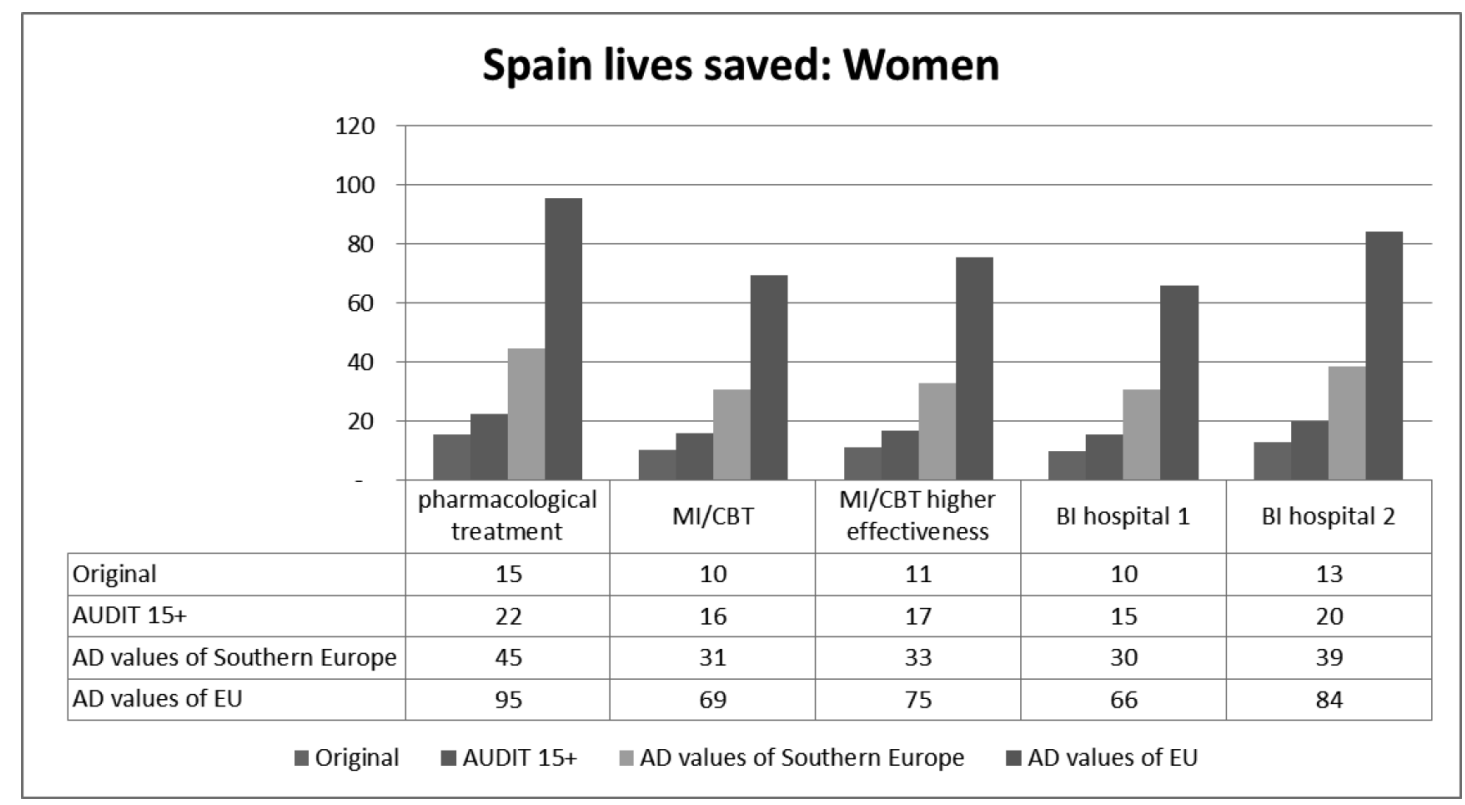

Figure 4: Results for pharmacological interventions in Spain assuming 40\% coverage (i.e. $40 \%$ of all people with $A D$ are treated): main analysis and sensitivity analyses assuming prevalence of $A D$ in Southern European region and prevalence of $A D$ in $E U$ - for women

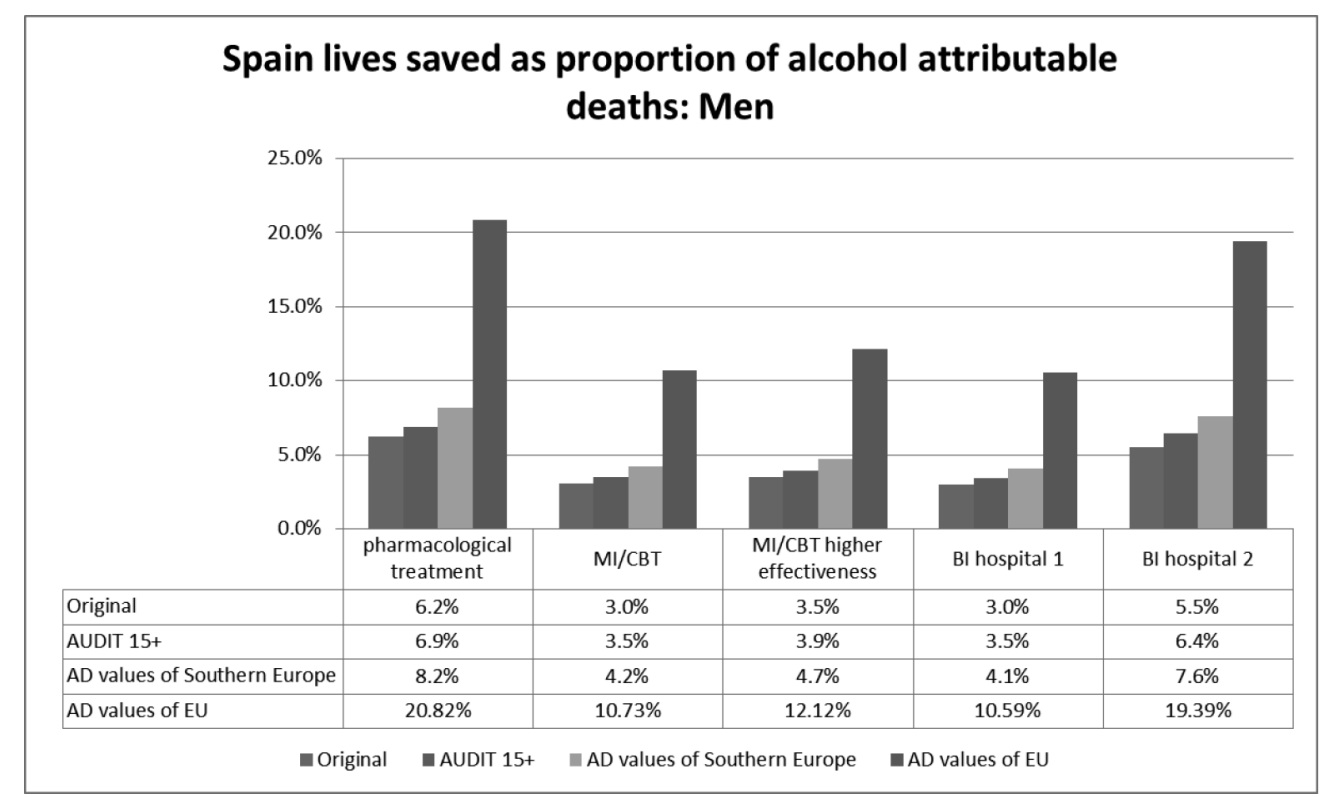

Figure 5: Results for pharmacological interventions in Spain assuming 40\% coverage (i.e. $40 \%$ of all people with $A D$ are treated): main analysis and sensitivity analyses assuming prevalence of $A D$ in Southern European region and prevalence of $A D$ in EU - for men as a proportion of alcoholattributable deaths 


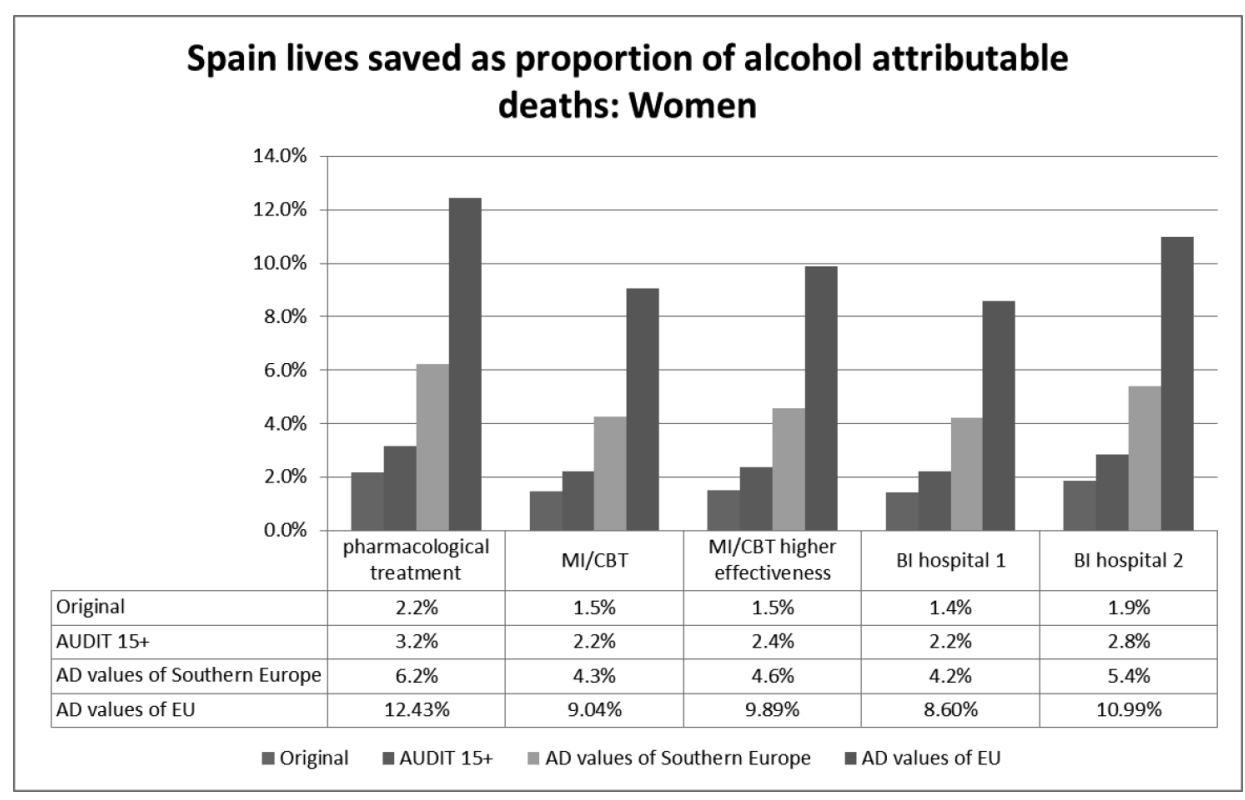

Figure 6: Results for pharmacological interventions in Spain assuming 40\% coverage (i.e. $40 \%$ of all people with $A D$ are treated): main analysis and sensitivity analyses assuming prevalence of $A D$ in Southern European region and prevalence of $A D$ in EU - for women as a proportion of alcohol-attributable deaths

result was true for all interventions modelled, even taking the most conservative assumptions of a low prevalence of AD. The size of the effect and the absolute number of deaths prevented depend on the number of treatments implemented (and this latter number depends on the prevalence of AD). Under assumptions of a prevalence of $A D$ at the level of the EU average, more than $20 \%$ of the alcohol-attributable deaths in men and more than $10 \%$ of the alcohol-attributable deaths in women could be prevented with pharmacological treatment, and slightly fewer deaths would be prevented if brief interventions were to be implemented in hospitals. Thus, increasing treatment rates is an important addition to the usual alcohol policy measures.

\section{Acknowledgements}

This work was supported by an unrestricted contract from Lundbeck A/S. In addition, WHO European Region financially supported the calculations of alcoholattributable harm, and the methodology for determination of alcohol-attributable fractions was developed within the Comparative Risk Assessment for alcohol of the Global Burden of Disease 2005 study. The statistics on alcohol attributable mortality and burden of disease follow our chapter in the publication of the WHO Regional Office for Europe on alcohol in the European region. We would like to acknowledge the provision of data from the latest WHO European survey on alcohol consumption and policy to all member states. Finally, the salary of JR was supported by the Ontario Ministry of Health and Long-Term Care.

\section{Competing interests}

JR had financial support for the submitted work from an unrestricted educational grant from Lundbeck; has received remuneration and travel expenses from Lundbeck for Board meetings in combination with Nalmefene, a pharmacological compound intended to treat alcohol dependence; no other relationships or activities that could appear to have influenced the submitted work. None of the funders had any role in study design; in the collection, analysis, and interpretation of data; in the writing of the report; and in the decision to submit the paper for publication. The authors have had full access to all the data in the study and had final responsibility for the decision to submit the paper for publication.

\section{References}

Anderson, P. \& Baumberg, B., (2006) Alcohol in Europe. A Public Health Perspective. United Kingdom: Institute of Alcohol Studies for the European Commission London.

Encuesta Domiciliaria sobre Alcohol y Drogas en España (EDADES). (2009) Delegación del Gobierno para el Plan Nacional sobre Drogas. Madrid: Ministerio de Sanidad, Política Social e Igualdad.

ESEMeD/MHEDEA 2000 Investigators. Prevalence of mental disorders in Europe: results from the European Study of the Epidemiology of Mental Disorders (ESEMeD) project. (2004). Acta Psychiatrica Scandinavica, 109, 21-27.

European Commission. (2010) EU citizens'attitudes towards alcohol. Special Eurobarometer 331. Brussels, Belgium: TNS.

Fierro, I., Ochoa, R., Yáñez, J. L., Valderrama, J. C., \& Álvarez, F. J. Mortalidad relacionada con el consumo de alcohol en España y en las comunidades autónomas en el año 2004. (2008). Revista Clínica Española, 208, 455462.

Grant, B. F., Compton, W. M., Crowley, T. J., Hasin, D. S., Helzer, J. E., Li, T. K. et al. Errors in assessing DSM-IV substance use disorders. (2007). Archives of General Psychiatry, 64, 379-380.

Gual, A. Alcohol in Spain: is it different? (2006). Addiction, 101, 1073-1077.

Gual, A., \& Colom, J. Why has alcohol consumption declined in countries of southern Europe? (1997). Addiction, 92 (Supplement 1), S21-S31. 
Guardia Serecigni, J., Arriero, M. A., Pastor, F. P., Menéndez, G. F., \& Guillamón, M. C. I. (2008). Alcoholismo. Guías Clínicas SOCIDROGALCOHOL basadas en la evidencia científica (2a edición). Barcelona, Spain: Socidraogalcohol.

Ivano, S., Garcia-Altes, R., \& Nebot, M. Social impact of abusive alcohol consumption in Spain: consumption, cost and policies. (2011). Revista Española de Salud Pública, 85, 2-141.

Jacobi, F., Wittchen, H., Holting, C., Hofler, M., Pfister, H., Muller, N. et al. Prevalence, co-morbidity and correlates of mental disorders in the general population: results from the German Health Interview and Examination Survey (GHS). (2004). Psychological Medicine, 34, 1-15.

Jacobi, F., Wittchen, H., Holting, C., Sommer, S., \& Lieb, R. Estimating the prevalence of mental and somatic disorders in the community: aims and methods of the German National Health Interview and Examination Survey. (2002). International Journal of Methods in Psychiatric Research, 11, 1-18.

Kessler, R. C. \& Üstün, B. (2008) The WHO world mental health surveys. Global perspectives of mental health surveys. First Edition. New York: Cambridge University Press.

Magill, M., \& Ray, L. A. Cognitive-behavioral treatment with adult alcohol and illicit drug users: ameta-analysis of randomized controlled trials. (2009). Journal of Studies on Alcohol and Drugs, 70, 516-527.

McQueen, J., Howe, T. E., Allan, L, Mains, D., \& Hardy, V. Brief interventions for heavy alcohol users admitted to general hospital wards. (2011). Cochrane Database of Systematic Reviews, 8 CD005191.

Ministerio de Sanidad y consumo. (2008) Prevención de los problemas derivados del alcohol. 1a Conferencia de prevención y promocion de la salud en la práctica clínica en España Madrid: Ministerio de Sanidad y consumo.

Plant, M., Miller, P., Plant, M., Gmel, G., Kuntsche, S., Bergmark, W. K. et al. The social consequences of binge drinking among 24- to 32-year-olds in six European countries. (2010). Substance Use \& Misuse, 45, 528-542.

Rehm, J., Baliunas, D., Borges, G. L. G., Graham, K., Irving, H. M., Kehoe, T. et al. The relation between different dimensions of alcohol consumption and burden of disease - An overview. (2010a). Addiction, 105, 817-843.

Rehm, J., Kehoe, T., Gmel, G., Stinson, F., Grant, B., \& Gmel, G. Statistical modeling of volume of alcohol exposure for epidemiological studies of population health: the example of the US. (2010b). Population Health Metrics, 8:3 doi:10.1186/1478-7954-8-3.

Rehm, J., Mathers, C., Popova, S., Thavorncharoensap, M., Teerawattananon, Y., \& Patra, J. Global burden of disease and injury and economic cost attributable to alcohol use and alcohol use disorders. (2009). Lancet, 373, 2223-2233.

Rehm, J., Rehn, N., Room, R., Monteiro, M., Gmel, G., Jernigan, D. et al. The global distribution of average volume of alcohol consumption and patterns of drinking. (2003). European Addiction Research, 9, 147-156.

Rehm, J., Room, R., Monteiro, M., Gmel, G., Graham, K., Rehn, N. et al. (2004). Alcohol Use. In Ezzati M., Lopez A.D., Rodgers A., y Murray C.J.L. (Eds.). Comparative quantification of health risks: global and regional burden of disease attributable to selected major risk factors. (pp. 959-1109). Geneva, Switzerland: World Health Organization.

Rehm, J., Shield, K., Rehm, M., Gmel, G. j., y Frick, U. (2012). Alcohol consumption, alcohol dependence, and attributable burden of disease: potential gains from effective interventions for alcohol dependence. Toronto, ON: Centre for Addiction and Mental Health.

Rehm, J., Taylor, B., y Room, R. Global burden of disease from alcohol, illicit drugs and tobacco. (2006). Drug and A/cohol Review, 25, 503-513.
Room, R.,y Mäkelä, K. Typologies of the cultural position of drinking. (2000). Journal of Studies on Alcohol, 61, 475-483.

Rösner, S., Hackl-Herrwerth, A., Leucht, S., Lehert, P., Vecchi, S., y Soyka, M. Acamprosate for alcohol dependence. (2010a). Cochrane Database of Systematic Reviews, 9 CD004332.

Rösner, S., Hackl-Herrwerth, A., Leucht, S., Vecchi, S., Srisurapanont, M., \& Soyka, M. Opioid antagonists for alcohol dependence. (2010b). Cochrane Database of Systematic Reviews, 12 CD001867.

Smedslund, G., Berg, R. C., Hammerstrom, K. T., Steiro, A., Leiknes, K. A., Dahl, H. M. et al. Motivational interviewing for substance abuse. (2011). Cochrane Database of Systematic Reviews, 5 CD008063.

Valencia-Martin, J. L., Galán, I., \& Rodriguez-Artalejo, F. Binge drinking in Madrid, Spain. (2007). Alcoholism: Clinical and Experimental Research, 31, 1723-1730.

World Health Organization. (2004). Global status report on alcohol and health. Geneva: World Health Organization.

World Health Organization. (2011). Global status report on alcohol and health. Geneva, Switzerland: World Health Organization.

\section{APPENDICIES (to be consulted at the web)}

Alcohol and general population indicators for Spain

Methods used to model alcohol-attributable mortality

Categories of alcohol-related disease and sources used for determining alcohol-attributable fractions

Overview of assumptions used when for modelling interventions effects

Overview of statistical methods used to model intervention 
Web appendix 1: Alcohol and general population indicators for Spain

\section{Country Indicators}

- $\quad$ Size (Size square KM): 503,370

- Population (2009): 47,087,000

- GDPPPP per capita (in \$US): 26,983

- Alcohol Exposure Indicators

- Lifetime Abstainers (2005): W: 24.7\%; M: 9.5\%

- Former Drinkers (2005): W: 31.6\%; M:23.4\%

- WHO at risk consumption (2009): W (40+ grams/day): $0.6 \% M_{i}(60+$ grams $/$ day $): 3.9 \%$

- Per capita consumption (unrecorded) [2009]: 13.1 I (1.4I)

- Pattern of Drinking Score (2009): 1 (out of a scale from 1 to 5 , with 1 being the best score)

- Alcohol-Attributable Harm (15-64 years of age; 2004)

- Mortality Alcohol-Attributable (per 100,000): W: 11.29; M: 40.85

- Percent mortality attributable to alcohol: W: 8.39\%; M: $12.34 \%$

- DALYS Alcohol-Attributable (per 100,000): W: 247.0; M: $1,086.9$

- Percent burden attributable to alcohol: W: 2.87\%; M: $9.43 \%$

- Prevalence Alcohol Dependence (18-65): W: 0.2\%; M: $1.2 \%$

- Alcohol Dependence Treatment Systems

Abstinence-based approach, but reduced drinking is acceptable; Cognitive Behavioural Therapy, Motivational Interviewing and Group Therapy treatment as the most frequently use psychotherapies are sometimes combined with pharmacotherapy (disulfiram, naltrexone, topiramate and acamprosate) 

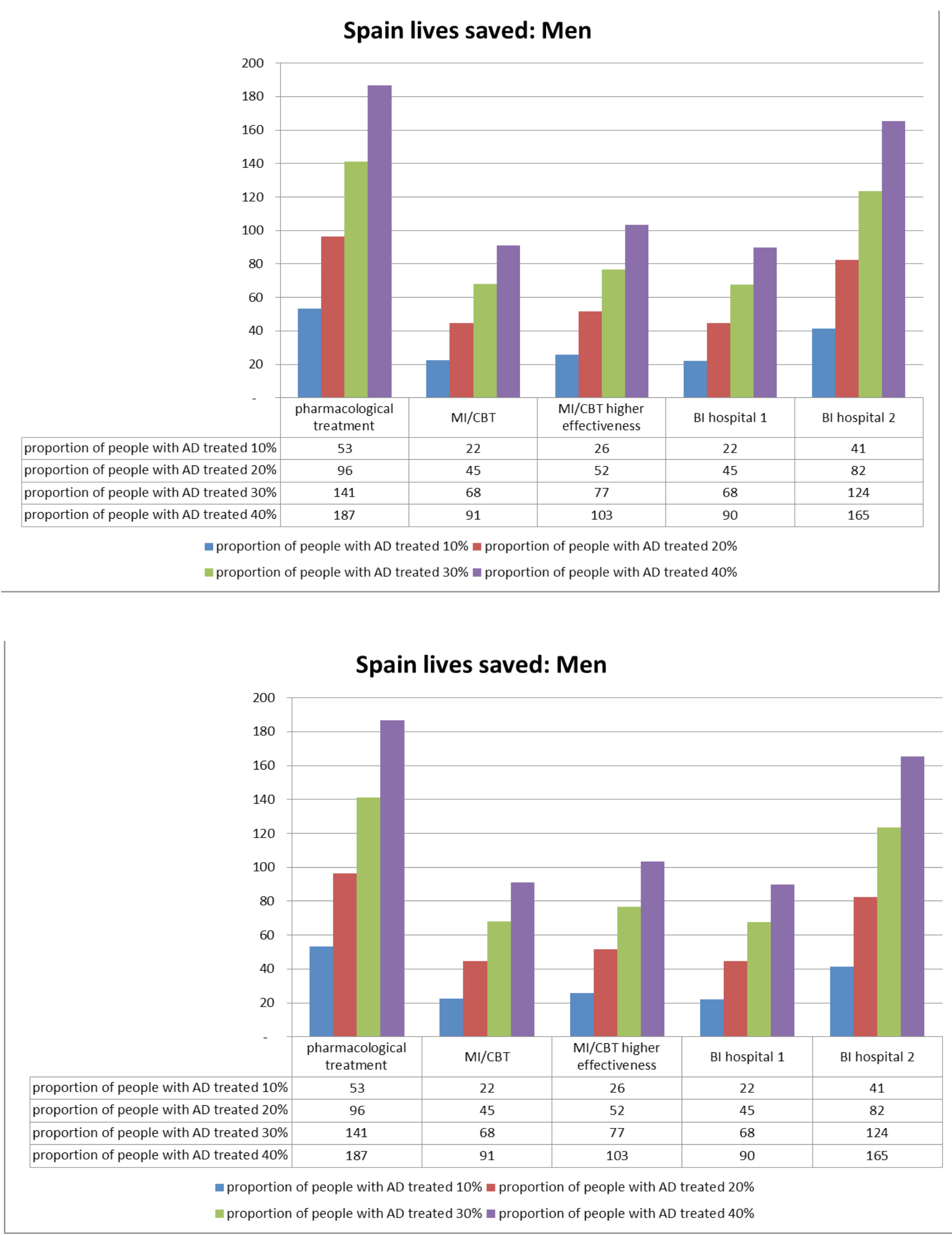


\section{Spain lives saved as proportion of alcohol attributable deaths: Men}

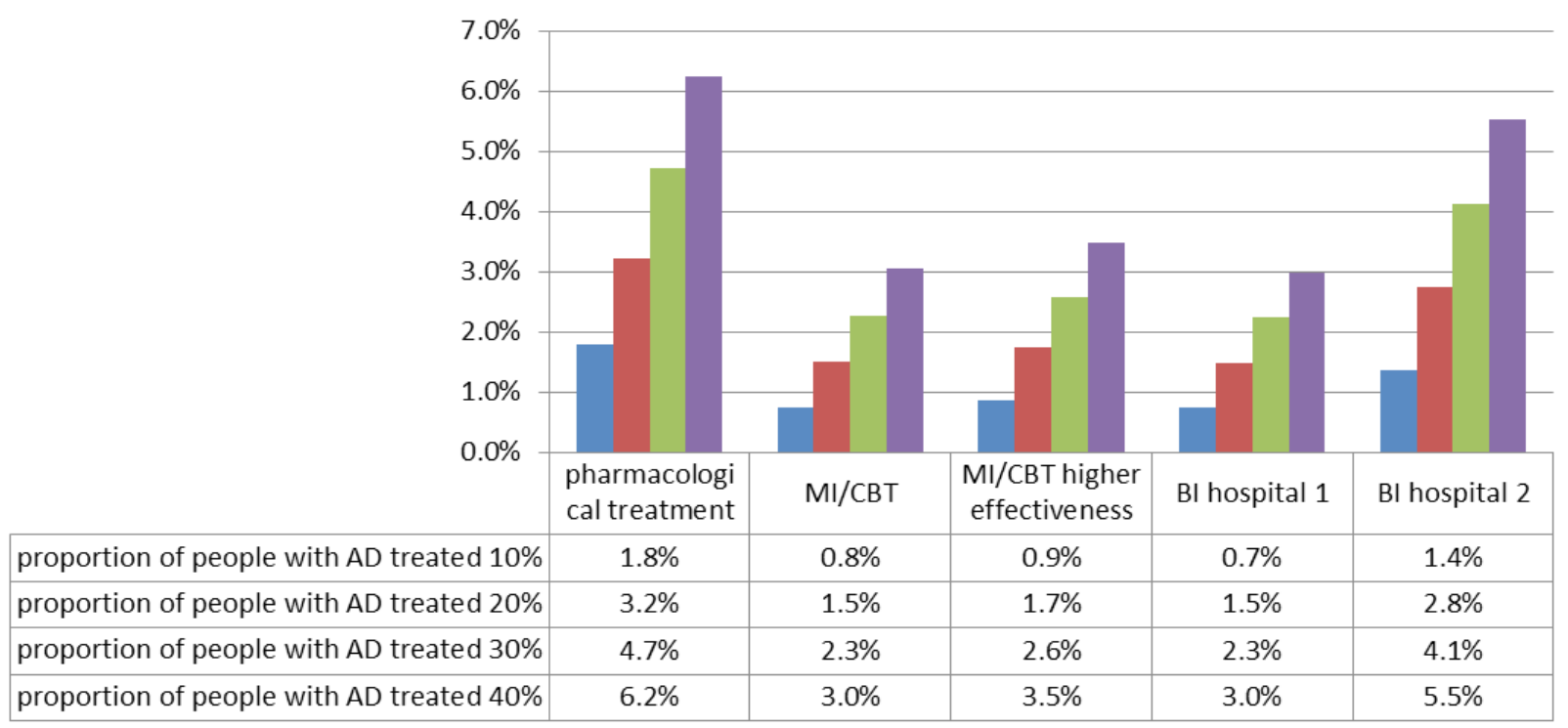

च proportion of people with AD treated $10 \%$ w proportion of people with AD treated $20 \%$

v proportion of people with AD treated $30 \%$ w proportion of people with AD treated $40 \%$

\section{Spain lives saved as proportion of alcohol attributable deaths: Women}

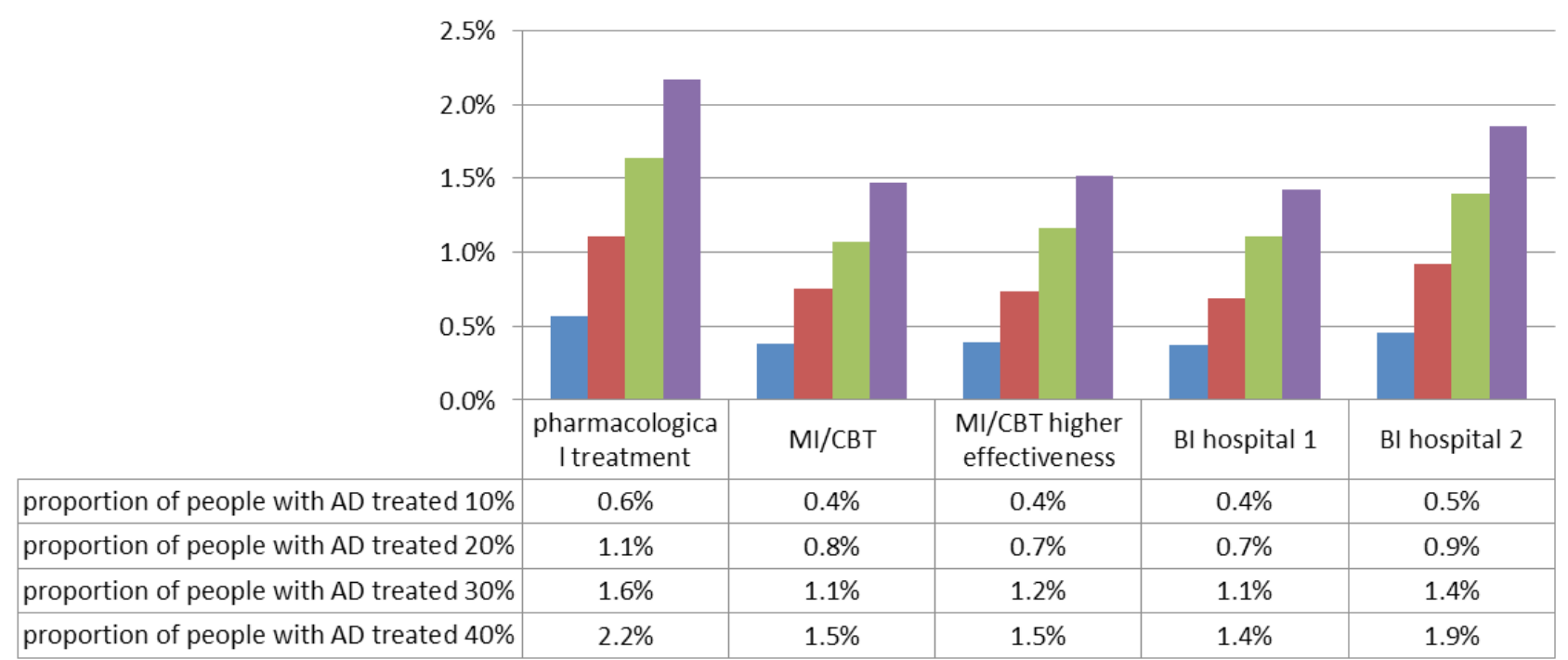

च proportion of people with AD treated $10 \%$ a proportion of people with AD treated $20 \%$

- proportion of people with AD treated $30 \%$ proportion of people with AD treated $40 \%$ 


\section{Web appendix 2: Methods used to model alcohol- attributable mortality}

\section{Deriving Alcohol-Attributable Fractions based on exposure and Relative Risks}

The number of deaths attributable to alcohol consumption (i.e. the number of deaths that would not have occurred if everyone was a lifetime abstainer) is calculated using an Alcohol-Attributable Fraction (AAF) (Murray y Lopez 1997; Rothman et al., 2008).

To calculate the number of deaths, Potential Years of Life Lost (PYLL), Years of Life lost to Disability (YLD), and Disability Adjusted Years of Life lost (DALYs) attributable to alcohol consumption we: (1) calculated the country-, age-, and sex-specific AAFs, and then (2) applied these AAFs to the corresponding mortality, PYLL, YLD and DALYs data.

\section{Step 1: Calculation of the AAFs by country, age, and sex}

\section{Definition of age categories}

Three age categories were used in our analysis so as to be comparable to the 2005 Global Burden of Disease (GBD) study: 15-34, 35-64 and 65 or older. (Harvard University et al., 2010).

\section{Countries included in the analysis}

Data from all 27 member states of the European Union (EU) were used in our analyses. Population estimates by country for 2004 and 2009 were based on data obtained from the 2008 revisions of the United Nations Population Division (United Nations Population Division 2009).

\section{Sources for modelling risk relations}

Sources for Relative Risk (RR) functions by ICD-10 code and GBD code are outlined in Web Appendix 3. These RRs are based on meta-analyses that report a continuous RR function by alcohol consumption exposure (see (Rehm et al., 2010) for an overview of the relationship between alcohol and various diseases, conditions and injuries).

\section{AAFs for chronic and infectious diseases, except ischemic heart disease}

The AAFs for chronic and infectious diseases, except ischemic heart disease, were calculated as follows:

$$
A A F=\frac{P_{a b s}+P_{\text {former }} R R_{\text {former }}+\int_{0}^{150} P_{\text {current }}(x) R R_{\text {current }}(x) d x-1}{P_{\text {abs }}+P_{\text {former }} R R_{\text {former }}+\int_{0}^{150} P_{\text {current }}(x) R R_{\text {current }}(x) d x}
$$

where $P_{\text {abs }}$ is the prevalence of lifetime abstainers, $P_{\text {former }}$ is the prevalence of former drinkers, $R R_{\text {former }}$ is the RR for former drinkers, $P_{\text {current }}$ is the prevalence of current drinkers who consume on average $x$ grams of alcohol, and $R R_{\text {current }}$ is the $R R$ given an average daily consumption of $x$ grams of alcohol.

\section{AAFs for ischemic heart disease}

Average volume of alcohol consumption and patterns of drinking are associated with the risk of ischemic heart disease (Puddey, Rakic, Dimmitt, y Beilin 1999; Rehm, Sempos, y Trevisan 2003). To model the risk of ischemic heart disease, we used an RR based on average volume of consumption ((Roerecke y Rehm 2012); see also (Corrao, Rubbiati, Bagnardi, Zambon, y Poikolainen 2000), or (Ronksley, Brien, Turner, Mukamal, y Ghali 2011) for similar results) for all individuals who did not engage in heavy drinking (see Table 3 above). For people with at least one heavy drinking occasion per month (see Table 3 above), we assumed no cardio-protective effect (Roerecke y Rehm 2010) (i.e. a RR of 1).

\section{Estimating the AAFs for people who sustain inju- ries due to other people's drinking, including low birth weight}

To estimate the mortality caused by low birth weight attributable to alcohol consumption, we modelled the alcohol consumption of pregnant women who drank the same amount of alcohol as pre-pregnancy and the alcohol consumption of pregnant women who drank less. The AAFs for low birth weight were calculated as follows:

$$
A A F=\frac{P_{a b s}+\int_{0}^{150} P_{\text {same }}(x) R R(x) d x+\int_{0}^{150} P_{\text {less }}(x) R R(x) d x-1}{P_{a b s}+\int_{0}^{150} P_{\text {same }}(x) R R(x) d x+\int_{0}^{150} P_{\text {less }}(x) R R(x) d x}
$$

where $P_{a b s}$ is the proportion of women who abstained from consuming alcohol while pregnant, $\mathrm{P}_{\text {same }}$ represents the proportion of pregnant women who consumed the same amount of alcohol as pre-pregnancy, and $P_{\text {less }}$ represents the proportion of pregnant women who consumed less alcohol than prepregnancy.

\section{AAFs for injuries}

\section{Estimating the AAFs for harms caused to oneself}

To estimate the morbidity from injuries that are attributable to alcohol consumption, we took into account two dimensions of alcohol consumption:

1. binge drinking (both the number of occasions and the amount consumed per occasion), and

2. alcohol consumption (on non-binge days).

We also modelled the time at risk for injury based on alcohol metabolism rates for men and women, according to methods outlined by Taylor and colleagues (Taylor, Shield, y Rehm 2011).

The AAFs for injuries attributable to alcohol consumption were calculated as follows:

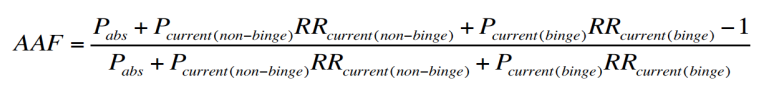


where $P_{\text {abs }}$ is the prevalence of current abstainers, and $P$ drinkers who engage in binge drinking and the prevalence of current drinkers who do not engage in binge drinking respectively. The RRs for current drinkers who engage in binge drinking, and current drinkers who do not engage in binge drinking were calculated as follows:

$$
\mathrm{RR}_{\text {current(non-binge) }}=\left(\mathrm{RR}_{\text {average }}-1\right) * \mathrm{P}_{\text {nonbingedays }}+1
$$

and:

$$
\begin{gathered}
R R_{\text {current }(\text { binge })} \\
=\left(R R_{\text {average }}-1\right) * P_{\text {nonbingedays }}+\left(R R_{\text {binge }}-1\right) * P_{\text {bingedays }}+1
\end{gathered}
$$

where the risk of injury on average drinking days $\left(R_{\text {average }}\right)$ was calculated as follows:

$$
R R_{\text {average }}=P_{\text {dayatrisk }}(x) *\left(R R_{\text {avg_non-binge }}(x)-1\right)+1
$$

and where the risk of injury on binge drinking days $\left(R_{\text {binge }}\right)$ was calculated as follows:

$$
R R_{\text {binge }}=P_{\text {dayatrisk }}(x) *\left(R R_{\text {binge }}(x)-1\right)+1
$$

where $P_{\text {dayatrisk }}$ is the proportion of a day at risk, and $R R_{\text {binge }}$ and $\mathrm{RR}_{\text {current }}$ are the relative risks for injury given an amount of alcohol consumed. $P_{\text {dayatrisk }}$ is calculated based on the average rate at which alcohol is metabolized.

To estimate the AAF for mortality from motor vehicle accidents, we multiplied the AAF for morbidity for motor vehicle accidents by $3 / 2$. Similarly, to estimate the AAF for mortality due to non-motor vehicle accidents, we multiplied the AAF for morbidity for non-motor vehicle accidents by $9 / 4$. These multipliers were based on two studies that compared blood alcohol levels of emergency room patients with blood alcohol levels obtained from coroners' reports of patients who died from an injury (Cherpitel 1994; Cherpitel 1996). The AAF for motor vehicle accidents for women was calculated by multiplying the AAF for motor vehicle accidents for men by the product of the per capita consumption of alcohol for women divided by the per capita consumption of alcohol for men.

\section{Estimating the AAFs for harms caused to others}

The AAFs for motor vehicle accidents caused by the drinking of others were calculated based on recent data reported by Laslett et al. (Laslett et al., 2010). The AAFs for the alcoholattributable injuries to others were calculated as follows:

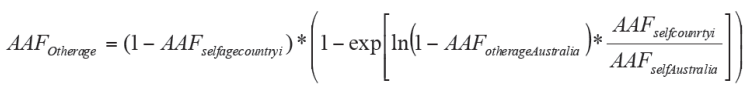

where $\mathrm{AAF}_{\text {otherage }}$ is the $\mathrm{AAF}$ for motor vehicle accident injuries caused by others, $A A F_{\text {selfcountryi }}$ is the AAF for motor vehicle accident injuries caused to oneself for an entire country $i$, and AAFselfagecountryi is the AAF for motor vehicle accident injuries caused to oneself for each specific age group. $A A F_{\text {selfAustralia }}$ is the $A A F$ for motor vehicle accident injuries caused to oneself in Australia, and $A A F_{\text {otherageAustralia }}$ is the AAF for motor vehicle accident injuries caused by others for each specific age group in Australia.

The AAFs for injuries caused by an assault by someone who has been drinking were calculated based on recent data reported by (Laslett et al., 2010). These AAFs were calculated as follows:

$$
\begin{gathered}
A A F_{\text {assaultagecountryi }} \\
=A A F_{\text {assaultageAustralia }} *\left(A A F_{\text {assaultcountryi }} / A A F_{\text {assaultaustralia }}\right)
\end{gathered}
$$

where $A A F_{\text {assaultagecountryi }}$ is the $A A F$ for deaths or injuries caused by assaults for an age group, $A A F_{\text {assaultcountryi }}$ is the AAF for deaths or injuries caused by assaults for an entire country, $A A F_{\text {assaultageAustralia }}$ is the AAF for deaths or injuries caused by assaults for each specific age group in Australia, and AAF saultAustralia is the AAF for deaths or injuries caused by assaults for Australia.

\section{Estimating the AAFs due to heavy drinking}

The fraction of deaths or DALYs attributable to heavy drinking (Heavy Drinker Attributable Fraction (HDAF)) was estimated as follows:

$$
H D A F=\frac{c \cdot P_{\text {form }} R R_{\text {form }}+\int_{x_{1}}^{150} P(x) R R(x) d x-\left(c \cdot P_{\text {form }}+\int_{x_{1}}^{150} P(x) d x\right)}{P_{a b s}+P_{\text {form }} R R_{\text {form }}+\int_{0}^{150} P(x) R R(x) d x}
$$

where $P_{\text {form }}$ is the proportion of former drinkers, $P(x)$ the prevalence of drinking a daily amount of alcohol $x_{1} P_{a b s}$ is the proportion of abstainers, $R R_{\text {form }}$ is the $\mathrm{RR}$ for former drinkers, and $R R(x)$ is the RR for drinkers associated with a daily alcohol intake of $x$. The variable $x_{1}$ is the threshold after which a drinker is considered a heavy drinker. In our case, $x_{1}$ is $60 \mathrm{~g} /$ day for men and $40 \mathrm{~g} /$ day for women.

To estimate the proportion of current heavy drinkers and their risk, we integrated the prevalence-risk ratio product from the heavy drinking threshold $\left(\mathrm{x}_{1}\right)$ to 150 . To estimate the proportion of former heavy drinkers, we multiplied the prevalence of former drinkers by a ratio of harm (harm among all current heavy drinkers compared to harm among all current drinkers (represented by the symbol c). This ratio was calculated as follows.

$$
c=\frac{\int_{x_{1}}^{150} P(x) R R(x) d x}{\int_{0}^{150} P(x) R R(x) d x}
$$

This calculation assumes that the proportion of risk of an outcome among former heavy drinkers as compared to all former drinkers is proportional to the risk of an outcome among heavy drinkers as compared to all current drinkers. HDAFs

Estimating the 95\% confidence intervals for the AAFs and

The 95\% confidence intervals (Cls) for the AAFs and HDAFs were estimated using a Monte Carlo type approach described by $\mathrm{Gmel}$ and colleagues (Gmel et al., 2011) for chronic and 
infectious diseases, and by Taylor and colleagues (Taylor, Shield, y Rehm 2011) for injuries. To estimate the variance for each AAF and HDAF, we used a set of 40,000 generated lowest level parameters and then used these sets of parameters to calculate 40,000 AAFs and HDAFs. We then calculated the variances of the resulting 40,000 AAFs and HDAFs to estimate the $95 \% \mathrm{Cls}$.

All statistical analyses and modelling were performed using $R$ version 2.11.1 (R Development Core Team 2011).

\section{Step 2: Application of the AAFs to region-specific mortality, PYLL, YLD and DALYs data}

This step requires multiplying the country-, age-, and sexspecific AAFs and HDAFs by each of mortality, PYLL, YLD, and DALYs data.

\section{Estimates of mortality and morbidity}

Mortality, PYLL, YLD, and DALYs were obtained from the 2005 GBD study (Harvard University et al., 2010). Full details on data, methods and cause categories for mortality, PYLL, YLD and DALYs are described elsewhere (Lopez et al., 2006; Lopez, Mathers, Ezzati, Jamison, y Murray 2006). Estimates of standardized rates for mortality data for 2004 were calculated using the 2008 revision of population estimates of WHO Member States prepared by the UN Population Division (United Nations Population Division 2007).

\section{Reference List}

Cherpitel, C. Alcohol and casualties: a comparison of emergency room and coroner data. (1994). Alcohol and Alcoholism, 29 211-218.

Cherpitel, C. Alcohol in fatal and nonfatal injuries: a comparison of coroner and emergency room data from the same country. (1996). Alcoholism: Clinical and Experimental Research, 20(2), 338-342.

Corrao, G., Rubbiati, L., Bagnardi, V., Zambon, A., y Poikolainen, K. Alcohol and coronary heart disease: A meta-analysis. (2000). Addiction, 95(10), 1505-1523.

Gmel, G. Jr., Shield, K. D., Frick, H., Kehoe, T., Gmel, G., y Rehm, J. Estimating uncertainty of alcohol-attributable fractions for infectious and chronic diseases. (2011). BMC Med Res Methodol, 11 48.

Harvard University, Institute for Health Metrics and Evaluation, John Hopkins University, University of Queensland, y World Health Organization. (2010) Global Burden of Diseases, Injuries, and Risk Factors Study (GBD 2005 Study) Operations manual. Seattle, WA: Institute for Health Metrics and Evaluation.

Laslett, A. M., Catalano, P., Chikritzhs, T., Dale, C., Doran, C., Ferris, J. et al. (2010) The range and magnitude of alcohol's harm to others. Fitzroy, Vic: Turning Point Alcohol \& Drug Centre.

Lopez, A. D., Mathers, C. D., Ezzati, M., Jamison, D. T., y Murray, C. J. L. Global and regional burden of disease and risk factors, 2001: Systematic analysis of population health data. (2006). Lancet, 367(9524), 1747-1757.
Lopez, A. D., Mathers, C. D., Ezzati, M., Jamison, D. T., y Murray, C. J. L. (2006) Global burden of disease and risk factors. New York \& Washington: The World Band and Oxford University Press.

Murray, C. J. L.,y Lopez, A. Global mortality, disability, and the contribution of risk factors: global burden of disease study. (1997). Lancet, 349 1436-1442.

Puddey, I. B., Rakic, V., Dimmitt, S. B., y Beilin, L. J. Influence of pattern of drinking on cardiovascular disease and cardiovascular risk factors a review. (1999). Addiction, 94 649-663.

R Development Core Team. (2011) R: A Language and Environment for Statistical Computing (version 2.13.0). Vienna, Austria: R Foundation for Statistical Computing.

Rehm, J., Baliunas, D., Borges, G. L. G., Graham, K., Irving, H. M., Kehoe, T. et al. The relation between different dimensions of alcohol consumption and burden of disease - An overview. (2010). Addiction, 105(5), 817-843.

Rehm, J., Sempos, C., y Trevisan, M. Average volume of alcohol consumption, patterns of drinking and risk of coronary heart disease - a review. (2003). Journal of Cardiovascular Risk, 10(1), 15-20.

Roerecke, M.y Rehm, J. Irregular heavy drinking occasions and risk of ischemic heart disease: a systematic review and meta-analysis. (2010). American Journal of Epidemiology, 171(6), 633-644.

Roerecke, M.,y Rehm, J. The cardioprotective association of average alcohol consumption and ischaemic heart disease: a systematic review and meta-analysis. (2012). Addiction, 107(7), 1246-1260.

Ronksley, P. E., Brien, S. E., Turner, B. J., Mukamal, K. J., y Ghali, W. A. Association of alcohol consumption with selected cardiovascular disease outcomes: a systematic review and meta-analysis. (2011). BMJ, 342 d671.

Rothman, K. J., Greenland, S., y Lash, T. L. (2008) Modern Epidemiology, 3rd ed. PA, USA: Lippincott Williams \& Wilkins.

Taylor, B., Shield, K., y Rehm, J. Combining best evidence: A novel method to calculate the alcohol-attributable fraction and its variance for injury mortality. (2011). BMCPublic Health, 11(1), 265.

United Nations Population Division. (2007) World Population Prospects The 2006 revision. New York: United Nations.

United Nations Population Division. (2009) World population prospectsthe 2008 revision. New York: United Nations. 
Web appendix 3. Categories of alcohol-related

disease and sources used for determining alcoholattributable fractions

\section{Conditions}

Infectious and parasitic diseases

$$
\text { Tuberculosis }
$$

Human immunodeficiency virus/ Acquired immune deficiency syndrome

Malignant neoplasm's

Mouth and oropharynx cancers

Esophageal cancer

Liver cancer

Laryngeal cancer

Breast cancer

Colon cancer

Rectal cancer

Diabetes

Diabetes mellitus

Neuro-psychiatric conditions

Alcoholic psychoses (part of AUD)

Alcohol abuse (part of AUD)

Alcohol dependence (part of AUD)

Epilepsy

Cardiovascular disease

Hypertensive disease

Ischemic heart disease

Cardiac arrhythmias

Hemorrhagic and other non-ischemic stroke

Ischemic stroke

Digestive diseases

Cirrhosis of the liver

Acute and chronic pancreatitis

Respiratory infections

Pneumonia

Conditions arising during the prenatal period
A15-A19

$\mathrm{C} 20$

ICD 10 Code

B20-B24

$\mathrm{C} 00-\mathrm{C} 14$

C15

$\mathrm{C} 22$

C32

C50

C18

E10-E14

F10.0, F10.3-F10.9

F10.1

F10.2

G40-G41

$|10-| 15$

$120-\mid 25$

147-149

I60-I62, 169.0, I69.1, I69.2

I63-I67, 169.3

K70, K74

$\mathrm{K} 85, \mathrm{~K} 86.1$

J10.0, J11.0, J12-J15, J18

P05-P07
Sources for Relative Risks

(Lönnroth, Williams, Stadlin, Jaramillo, y Dye 2008); for causal relationship see: (Rehm et al., 2009)

(Gmel, Shield, y Rehm 2011)

(Baan et al., 2007) (based on Relative Risks from (Corrao, Bagnardi, Zambon, y La Vecchia 2004; International Agency for Research on Cancer 2010))

(Baan et al., 2007; International Agency for Research on Cancer 2010) (based on Relative Risks from (Corrao, Bagnardi, Zambon, y La Vecchia 2004))

(Baan et al., 2007; International Agency for Research on Cancer 2010) (based on Relative Risks from (Corrao, Bagnardi, Zambon, y La Vecchia 2004))

(Baan et al., 2007; International Agency for Research on Cancer 2010) (based on Relative Risks from (Corrao, Bagnardi, Zambon, y La Vecchia 2004))

(Baan et al., 2007; International Agency for Research on Cancer 2010) (based on Relative Risks from (Corrao, Bagnardi, Zambon, y La Vecchia 2004))

(Baan et al., 2007; International Agency for Research on Cancer 2010) (based on Relative Risks from (Corrao, Bagnardi, Zambon, y La Vecchia 2004))

(Baan et al., 2007; International Agency for Research on Cancer 2010) (based on Relative Risks from (Corrao, Bagnardi, Zambon, y La Vecchia 2004))

(Baliunas et al., 2009)

100\% AAF per definition

100\% AAF per definition

100\% AAF per definition

(Samokhvalov, Irving, Mohapatra, y Rehm 2010)

(Taylor et al., 2009)

(Roerecke y Rehm 2012), for volume, (Roerecke y Rehm 2010) for pattern

(Samokhvalov, Irving, y Rehm 2010a)

(Patra et al., 2010)

(Patra et al., 2010)

(Rehm et al., 2010)

(Irving, Samokhvalov, y Rehm 2009)

(Samokhvalov, Irving, y Rehm 2010b)

(Patra et al., 2011) 
Unintentional injuries

Motor vehicle accidents

Poisonings

Falls

Fires

Drowning

Other unintentional injuries

Intentional injuries

Self-inflicted injuries

Homicide

Other intentional injuries
$\mathrm{X} 40-\mathrm{X} 49$

W00-W19

X00-X09

W65-W74

tRest of V-series and W20-W64, W 75-W99, X10-X39, X50-X59, Y40-Y86 $Y 88$, and $Y 89$

$\mathrm{X} 60-\mathrm{X} 84$ and $\mathrm{Y} 87.0$

X85-Y09, Y87.1
(Taylor et al., 2010) for Relative Risk, methodology adopted from (Taylor, Shield, y Rehm 2011)

(Taylor et al., 2010) for Relative Risk, methodology adopted from (Taylor, Shield, y Rehm 2011)

(Taylor et al., 2010) for Relative Risk, methodology adopted from (Taylor, Shield, y Rehm 2011)

(Taylor et al., 2010) for Relative Risk, methodology adopted from (Taylor, Shield, y Rehm 2011)

(Taylor et al., 2010) Relative Risk, methodology adopted from (Taylor, Shield, y Rehm 2011

(Taylor et al., 2010) for Relative Risk, methodology adopted from (Taylor, Shield, y Rehm 2011)

(Taylor et al., 2010) for Relative Risk, methodology adopted from (Taylor, Shield, y Rehm 2011)

(Taylor et al., 2010) for Relative Risk, methodology adopted from (Taylor, Shield, y Rehm 2011)

(Taylor et al., 2010) for Relative Risk, methodology adopted from (Taylor, Shield, y Rehm 2011)

(Taylor et al., 2010) for Relative Risk, methodology adopted from (Taylor, Shield, y Rehm 2011)

§ V021-V029, V031-V039, V041-V049, V092, V093, V123-V129, V133-V139, V143-V149, V194-V196, V203-V209, V213-V219, V223-V229, V233-V239, V243-V249,V253-V259, V263-V269, V273- V279, V283-V289, V294-V299, V304-V309, V314-V319, V324-V329, V334-V339, V344-V349, V354-V359, V364-V369, V374-V379, V384-V389, V394-V399, V404-V409, V414-V419, V424-V429, V434-V439, V444-V449, V454-V459, V464- V469, V474-V479, V484-V489, V494-V499, V504-V509, V514-V519, V524-V529, V534-V539, V544-V549, V554-V559, V564-V569, V574-V579, V584-V589, V594-V599, V604-V609, V614-V619, V624-V629, V634-V639, V644-V649, V654- V659, V664-V669, V674-V679, V684-V689, V694-V699, V704-V709, V714-V719, V724-V729, V734-V739, V744-V749, V754-V759, V764-V769, V774-V779, V784-V789, V794-V799, V803-V805, V811, V821, V830-V833, V840-V843, V850- V853, V860-V863, V870-V878, V892. + Rest of $\mathrm{V}=\mathrm{V}$-series MINUS §. 


\section{Reference List}

Baan, R., Straif, K., Grosse, Y., Secretan, B., El Ghissassi, F., Bouvard, V. et al. Carcinogenicity of alcoholic beverages. (2007). Lancet Oncology, 8(4), 292-293.

Baliunas, D., Taylor, B., Irving, H., Roerecke, M., Patra, J., Mohapatra, S. et al. Alcohol as a risk factor for type 2 diabetes - A systematic review and meta-analysis. (2009). Diabetes Care, 32(11), 2123-2132.

Corrao, G., Bagnardi, V., Zambon, A., y La Vecchia, C. A meta-analysis of alcohol consumption and the risk of 15 diseases. (2004). Preventive Medicine, 38 613-619.

Gmel, G., Shield, K., y Rehm, J. Developing a methodology to derive alcohol-attributable fractions for HIV/AIDS mortality based on alcohol's impact on adherence to antiretroviral medication. (2011). Population Health Metrics, 9(1), 5.

International Agency for Research on Cancer. (2010) Alcoholic beverage consumption and ethyl carbamate (urethane). IARCMonograph 96 on the Evaluation of Carcinogenic Risks to Humans. Lyon, France: International Agency for Research on Cancer (IARC).

Irving, H. M., Samokhvalov, A., y Rehm, J. Alcohol as a risk factor for pancreatitis. A systematic review and meta-analysis. (2009). Journal of the Pancreas, 10(4), 387-392.

Lönnroth, K., Williams, B., Stadlin, S., Jaramillo, E., y Dye, C. Alcohol use as a risk factor for tuberculosis - a systematic review. (2008). BMC Public Health, 8289.

Patra, J., Taylor, B., Irving, H., Roerecke, M., Baliunas, D., Mohapatra, S. et al. Alcohol consumption and the risk of morbidity and mortality from different stroke types - a systematic review and meta-analysis. (2010). BMC Public Health, 10(1), 258.

Patra, J., Bakker, R., Irving, H., Jaddoe, V. W. V., Malini, S., y Rehm, J. Dose-response relationship between alcohol consumption before and during pregnancy and the risks of low birthweight, preterm birth and small for gestational age (SGA)-a systematic review and meta-analyses. (2011). BJOG: International Journal of Obstetrics and Gynaecology, 118(12), 1411-1421.

Rehm, J., Kehoe, T., Gmel, G., Stinson, F., Grant, B., y Gmel, G. Statistical modeling of volume of alcohol exposure for epidemiological studies of population health: the example of the US. (2010). Population Health Metrics, 83.

Rehm, J., Mathers, C., Popova, S., Thavorncharoensap, M., Teerawattananon, Y., y Patra, J. Global burden of disease and injury and economic cost attributable to alcohol use and alcohol use disorders. (2009). Lancet, 373(9682), 2223-2233.

Roerecke, M.,y Rehm, J. Irregular heavy drinking occasions and risk of ischemic heart disease: a systematic review and meta-analysis. (2010). American Journal of Epidemiology, 171(6), 633-644.

Roerecke, M.y Rehm, J. The cardioprotective association of average alcohol consumption and ischaemic heart disease: a systematic review and meta-analysis. (2012). Addiction, [Epub ahead of print].

Samokhvalov, A. V., Irving, H., Mohapatra, S., y Rehm, J. Alcohol consumption, unprovoked seizures and epilepsy: a systematic review and meta-analysis. (2010). Epilepsia, 51(7), 1177-1184.

Samokhvalov, A. V., Irving, H. M., y Rehm, J. Alcohol as a risk factor for atrial fibrillation: a systematic review and meta-analysis. (2010a). European Journal of Cardiovascular Prevention \& Rehabilitation, 17(6), 706-712.
Samokhvalov, A. V., Irving, H. M., y Rehm, J. Alcohol consumption as a risk factor for pneumonia: systematic review and meta-analysis. (2010b). Epidemiology and Infection, 138(12), 1789-1795.

Taylor, B., Irving, H. M., Baliunas, D., Roerecke, M., Patra, J., Mohapatra, S. et al. Alcohol and hypertension: gender differences in doseresponse relationships determined through systematic review and meta-analysis. (2009). Addiction, 104(12), 1981-1990.

Taylor, B., Irving, H. M., Kanteres, F., Room, R., Borges, G., Cherpitel, C. et al. The more you drink, the harder you fall: a systematic review and meta-analysis of how acute alcohol consumption and injury or collision risk increase together. (2010). Drug and Alcohol Dependence, 110(1-2), 108-116.

Taylor, B., Shield, K., y Rehm, J. Combining best evidence: A novel method to calculate the alcohol-attributable fraction and its variance for injury mortality. (2011). BMCPublic Health, 11(1), 265. 


\section{Web appendix 4. Overview of assumptions used}

when for modelling interventions

\begin{tabular}{|c|c|c|c|}
\hline Interventions & Main results (effects assumed to be stable for 1 year) & Risk Relations & Sources \\
\hline $\mathrm{MI}$ and $\mathrm{CBT} 1$ & $\begin{array}{l}\text { For } \mathrm{Ml} \text { an average drop of } 15.8 \mathrm{~g} \text { of pure alcohol per day was assumed (mea- } \\
\text { sured against no intervention; } 95 \% \mathrm{Cl} \text { from }-9.6 \mathrm{~g} \text { to } \\
-21.8 \mathrm{~g} \text { of pure alcohol). The effect after one year was very small and not sig- } \\
\text { nificant (average: } 1.2 \mathrm{~g} \text { of pure alcohol reduction per day), the average effect } \\
\text { over the year was a } 3.2 \mathrm{~g} \text { reduction of pure alcohol per day ( } 95 \% \mathrm{Cl} \text { : } \\
-1.2 \mathrm{~g} \text { to }-5.2 \mathrm{~g} \text { of pure alcohol per day). } \\
\text { For CBT almost the same effect was found in studies with a no-treatment } \\
\text { control as the comparison condition ( } 15.9 \mathrm{~g} \text { of pure alcohol per day). In addi- } \\
\text { tion, Project Match did not find any significant differences (Project MATCH } \\
\text { Research Group 1997) between Ml and CBT. } \\
\text { We modelled the results based on a drop of } 15.8 \mathrm{~g} \text { per day over the year. }\end{array}$ & \multirow{4}{*}{$\begin{array}{l}\text { The usual dose-dependent risk relations } \\
\text { between average consumption of alcohol } \\
\text { and disease outcomes were used, multi- } \\
\text { plied by } 2 \text { to account for the overall higher } \\
\text { mortality risk of people with AD (Harris y } \\
\text { Barraclough 1998). For injury, the RR from } \\
\text { (Harris y Barraclough 1998) was used for } \\
\text { AD and the risks from (Corrao, Bagnardi, } \\
\text { Zambon, y La Vecchia 2004) for non- } \\
\text { dependent people. }\end{array}$} & $\begin{array}{l}\text { MI: (Smedslund et al., 2011) } \\
\text { CBT: (Magill y Ray 2009) }\end{array}$ \\
\hline $\mathrm{Ml}$ and $\mathrm{CBT} 2$ & $\begin{array}{l}\text { An average drop of } 21.8 \mathrm{~g} \text { of pure alcohol per day was assumed as the upper } \\
\text { limit of the } \mathrm{Cl} \text { for } \mathrm{MI} / \mathrm{CBT} \text { (see above). We assumed proportional Cls compared } \\
\text { to the first MI/CBT scenario. }\end{array}$ & & (Smedslund et al., 2011) \\
\hline BI 2 & $\begin{array}{l}\text { An average reduction of the RR for mortality by } 0.6 \text { ( } 95 \% \text { Cl: } 0.40 \text { to } 0.91) \text {. } \\
\text { This scenario represents the "best case" for BI, as hospitalization is linked to } \\
\text { mortality, and AD plays an important role in mediating and moderating this } \\
\text { premature mortality (e.g. (O'Brien et al., 2007; De Lorenze, Weisner, Tsai, Satre, } \\
\text { y Quesenberry 2011)). However, similar effects were obtained in an meta- } \\
\text { analyses on all Bls (Cuijpers, Riper, y Lemmers 2004). }\end{array}$ & & $\begin{array}{l}\text { (McQueen, Howe, Allan, Mains, y } \\
\text { Hardy 2011) }\end{array}$ \\
\hline $\begin{array}{l}\text { Pharmacological therapy } \\
\text { (for simulation, the effects } \\
\text { of Randomized Controlled } \\
\text { Trials of acamprosate and } \\
\text { opioid antagonist treat- } \\
\text { ments were combined }\end{array}$ & $\begin{array}{l}\text { Overall, for } 55.0 \% \text { of the patient population a reduction in drinking by } 13 \% \text { on } \\
\text { average; for } 18.1 \% \text { of the patient population there was a reduction in drinking } \\
\text { by } 50 \% \text {; and for } 26.8 \% \text { of the population abstinence was the result. }\end{array}$ & & $\begin{array}{l}\text { Pooled estimates of (Rösner et al., } \\
\text { 2010b; Rösner et al., 2010a). For } \\
\text { this simulation we are concerned } \\
\text { with the differences in con- } \\
\text { sumption between baseline and } \\
\text { follow-up in the group receiving } \\
\text { medications only. }\end{array}$ \\
\hline
\end{tabular}

\section{Reference List}

Corrao, G., Bagnardi, V., Zambon, A., y La Vecchia, C. A meta-analysis of alcohol consumption and the risk of 15 diseases. (2004). Preventive Medicine, 38 613-619.

Cuijpers, P., Riper, H., y Lemmers, L. The effects on mortality of brief interventions for problem drinking: a meta-analysis. (2004). Addiction, 99(7), 839-845.

De Lorenze, G. N., Weisner, C., Tsai, A. L., Satre, D. D., y Quesenberry, C. P. J. Excess mortality among HIV-infected patients diagnosed with substance use dependence or abuse receiving care in a fully integrated medical care program. (2011). Alcoholism: Clinical and Experimental Research, 35(2), 203-210.

Harris, E. C.,y Barraclough, B. Excess mortality of mental disorder. (1998). British Journal of Psychiatry, 173 11-53.

Magill, M.y Ray, L. A. Cognitive-behavioral treatment with adult alcohol and illicit drug users: ameta-analysis of randomized controlled trials. (2009). JStud Alcohol Drugs, 70(4), 516-527.

McQueen, J., Howe, T. E., Allan, L., Mains, D., y Hardy, V. Brief interventions for heavy alcohol users admitted to general hospital wards. (2011). Cochrane Database of Systematic Reviews, 8 CD005191.

O'Brien, J. M. J., Lu, B., Ali, N. A., Martin, G. S., Aberegg, S. K., Marsh, C. B. et al. Alcohol dependence is independently associated with sepsis, septic shock, and hospital mortality among adult intensive care unit patients. (2007). Critical Care Medicine, 35(2), 345-350.
Project MATCH Research Group. Matching alcoholism treatment to client heterogeneity: Project MATCH posttreatment drinking outcomes. (1997). Journal of Studies on Alcohol, 58 7-30.

Room, R., Babor, T., y Rehm, J. Alcohol and public health: a review. (2005). Lancet, 365 519-530.

Rösner, S., Hackl-Herrwerth, A., Leucht, S., Lehert, P., Vecchi, S., y Soyka, M. Acamprosate for alcohol dependence. (2010a). Cochrane Database of Systematic Reviews, 9 CD004332.

Rösner, S., Hackl-Herrwerth, A., Leucht, S., Vecchi, S., Srisurapanont, M., y Soyka, M. Opioid antagonists for alcohol dependence. (2010b). Cochrane Database of Systematic Reviews, 12 CD001867.

Smedslund, G., Berg, R. C., Hammerstrom, K. T., Steiro, A., Leiknes, K. A., Dahl, H. M. et al. Motivational interviewing for substance abuse. (2011). Cochrane Database of Systematic Reviews, 5 CD008063. 


\section{Web appendix 5. Overview of statistical methods}

used to model intervention effects

To estimate the resulting effects of interventions on mortality, we modelled the effects of the interventions on average daily alcohol consumption and binge consumption for each country. Modelling of alcohol consumption was accomplished using 100,000 data points or "people," randomly generated using the Gamma distribution associated with the country's alcohol consumption (see (Rehm et al., 2010)). Data were capped at $150 \mathrm{~g} /$ day, but sensitivity analyses showed that uncapped data would not lead to different results or conclusions (Rehm et al., 2010; Kehoe, Gmel, Shield, Gmel, y Rehm 2012). Lifetime abstainers and former drinkers were modelled proportionally by applying the ratio of their respective prevalence to the prevalence of drinkers (i.e. the 100,000 total number of data points). It was assumed that the prevalence of people with Alcohol Dependence (AD) among current drinkers in each population was modelled in equal parts to the right and to the left of a threshold value that was fixed at $72 \mathrm{~g} /$ day for men and $48 \mathrm{~g} /$ day for women. For the effects of treatment, we assumed that only those people with AD above the threshold value would potentially undergo interventions to reduce harmful alcohol consumption. Simulated individuals with $A D$ who were treated using different interventions were chosen randomly.

Scenarios were modelled assuming that 10\%, 20\%, 30\%, or $40 \%$ of all people with $A D$ underwent treatment. For each intervention, the average alcohol intake of the selected individuals (modelled as data points) was decreased by the amount specified in web appendix 4 . AAFs and the resulting decrease in mortality based on the above-noted treatment scenarios were then computed by applying the RR for various diseases to each data point (see appendix 2 for risk modelling methodology).

\section{Reference List}

Kehoe, T., Gmel, G. j., Shield, K., Gmel, G. S., y Rehm, J. Modelling alcohol consumption as a distribution and determining the impact of the distribution on estimated alcohol-attributable harms. (2012). Population Health Metrics, 10(1), 6.

Rehm, J., Kehoe, T., Gmel, G., Stinson, F., Grant, B., y Gmel, G. Statistical modeling of volume of alcohol exposure for epidemiological studies of population health: the example of the US. (2010). Population Health Metrics, 83. 